\title{
Switching Transformation for Soft Pneumatic Adaptive Shading
}

\author{
Rakhmat F. Aditra ${ }^{1, *}$, Paolo Beccarelli ${ }^{1}$ and Carlos Jimenez-Bescos ${ }^{1}$ \\ ${ }^{1}$ University of Nottingham, \\ Department of Architecture and Built Environment, \\ United Kingdom \\ *e-mail: rakhmat.aditra@nottingham.ac.uk
}

\begin{abstract}
Soft pneumatic systems are one of the alternatives for adaptive building envelopes. They use air under pressure to obtain a movement to change the level of permeability of the façade of a building exposed to solar radiation. Despite the environmental potential of this technical solution, there is limited publications focused on soft pneumatic systems. Soft pneumatic systems are mentioned, briefly, in several publications on adaptive systems [1],[2] but there are limited details on switchable fritted layers applied to inflated ETFE cushions for architectural applications [3]. Based on the literature review, it was found that switching transformation type was rarely developed compared with other transformation type. It was only found in the switchable fritted layers.

This paper presents the research on an external shading based on a switching soft pneumatic adaptive system and describes its structural and energy-saving performance. External shading was chosen due to its advantages over internal shading which are (1) its location enabling it to disperse heat to the exterior environment, and (2) its aesthetic potential. The structural performance was analyzed with two methods: (1) a 2D structural numerical model, and (2) a Finite Element Analysis. The research includes energy simulations on a single zone office building located in a tropical and subtropical climate.

The structural analysis shows that the switching soft pneumatic adaptive shading system with pneumatic pressure of $8 \mathrm{kPa}$ could be used conservatively up to a basic velocity pressure of $424 \mathrm{~Pa}$, which is suitable for a three-story building in a flat city terrain such as London. The stiffness could be controlled by the level of pressure. In addition, the pumping pressure could be responsively controlled to minimize the energy used and leakage of air. The building energy simulation shows that the use of the proposed system could decrease the building energy up to $48 \%$.
\end{abstract}

\section{REFERENCES}

[1] A. Zarzycki and M. Decker, "Climate-adaptive buildings: Systems and materials," Int. J. Archit. Comput., vol. 17, no. 2, pp. 166-184, (2019).

[2] R. Velasco, A. P. Brakke, and D. Chavarro, "Dynamic Façades and Computation: Towards an Inclusive Categorization of High Performance Kinetic Façade Systems," in CAAD future proceedings: Computer-Aided Architectural Design Futures. The Next City - New Technologies and the Future of the Built Environment. pp. 172-191, (2015).

[3] J. F. Flor, Y. Wu, P. Beccarelli, and J. Chilton, "Dynamic environmental control mechanisms for pneumatic foil constructions," E3S Web Conf., vol. 22, (2017). 